\title{
Assessment of dental condition in young Polish adults using the BEWE index
}

\author{
SYLWIA PRZYBYSZEWSKA-PARDAK ${ }^{\mathrm{B}, \mathrm{D}-\mathrm{F}}$, MAGDALENA GROCH ${ }^{\mathrm{B}, \mathrm{D}-\mathrm{F}}$, JOLANTA E. LOSTER ${ }^{\mathrm{A}, \mathrm{C}-\mathrm{F}}$, \\ ORCID ID: 0000-0001-5170-8429 \\ ORCID ID: 0000-0002-0224-2199 \\ ORCID ID: 0000-0002-8759-0810
}

ANETA WIECZOREKA, D-F

ORCID ID: 0000-0003-2506-7394

Department of Prosthodontics, Institute of Dentistry, Medical College, Jagiellonian University, Cracow, Poland

A - Study Design, B - Data Collection, C - Statistical Analysis, D - Data Interpretation, E - Manuscript Preparation, F - Literature

Search, G - Funds Collection

Summary Background. The amount of low-pH food and drink consumed by young people continues to increase, resulting in an increasing number of people with dental erosion.

Objectives. The aim of the study was to use the BEWE index to assess the level of dental erosion of young Polish adults.

Material and methods. Plaster casts of the maxilla and the mandible and intraoral photographs were taken from volunteers 16.7 to 19.3 years of age and evaluated. They were examined for the presence of symptoms indicating the occurrence of erosive processes. The Basic Erosive Wear Examination (BEWE) index was used to record the lesions. One person evaluated all the models and pictures after prior calibration.

Results. The BEWE index was evaluated on 251 pairs of models and images. Erosion symptoms were found to occur in $43.43 \%$ of the entire study group, representing 109 examined subjects. With most erosion symptoms, the lesions consisted of small amounts of tissue loss in one of the examined sextants. There was a slightly higher prevalence of erosive lesions on the male tooth (45.59\%) than on the female $(42.62 \%)$, with no statistical significance. The value of the cumulative BEWE index for individuals varied from 0 to 3 , being 0 to 2 in $98.01 \%$ of cases (no risk of erosion) and 3 in $1.99 \%$ (low risk).

Conclusions. The risk of erosion among the studied adolescents was at a similar level as in other countries and occurred slightly more often in men than in women.

Key words: prevalence, tooth erosion, young adult.

Przybyszewska-Pardak S, Groch M, Loster JE, Wieczorek A. Assessment of dental condition in young Polish adults using the BEWE index. Fam Med Prim Care Rev 2020; 22(4): 307-311, doi: https://doi.org/10.5114/fmpcr.2020.98256.

\section{Background}

Non-carious lesions of hard dental tissues represent a problem in modern dental practice, which may be caused by abrasion (due to the mechanical action of external factors, such as tooth brushing), attrition (wear through tooth-tooth friction), abfraction (the result of tension and compression around the cementoenamel junction) and erosion. Erosion is associated with the action of a chemical agent, while the remaining forms of tooth damage are the result of mechanical factors.

We can define erosion as a loss of hard tissues caused by action on the surface of the teeth, of acids of external or internal origin or chelation without the presence of dental plaque [1]. Erosive lesions are associated with an initial loss of hardness of the enamel surface. The thickness of the softened enamel layer depends on the type of acid and the duration of its action. The enamel crystals then dissolve layer by layer, resulting in irreversible tissue loss. In advanced stages, dentin and pulp may be denuded [2].

Erosive acids may be of extrinsic origin (diet, environment) or intrinsic origin (acidic contents of the stomach) [3]. An acid's erosive potential depends not only on its $\mathrm{pH}$, but also on its buffering capacity, the type of acid (and its pKa values - i.e. its acid power, which refers to the capacity for the hydrogen ion and the anion to dissociate), its adhesion to dental surfaces, its chelating properties and the concentration of calcium, phosphates and fluorides in the active substance [4]

Extrinsic acids are primarily found in fruit and fruit juices, while phosphoric acid and ascorbic acid are found in soft drinks [5].
Erosion may also be caused by acids in the air that arise from the working environment, by water in swimming pools where hydrochloric acid forms as a result of the gaseous chlorination of water and by oral medicines with a low $\mathrm{pH}[6,7]$. Holding acidic fluids in the mouth, or rinsing with acidic solutions, prolongs the exposure of the teeth to acids, increasing the risk of erosion $[8,9]$. There is also a higher prevalence of erosive lesions in people on a diet rich in raw food [10], while no such relationship was found in vegetarians [11].

An important role in the formation of erosion is also played by intrinsic acids. The main endogenous factor causing erosion is acidic gastric content entering the mouth by vomiting, regurgitation, gastroesophageal reflux or rumination (the return of food from the stomach to the mouth, where it is re-chewed and re-swallowed) [12]. Vomiting may occur as a result of eating disorders (such as anorexia nervosa or bulimia), pregnancy or alcoholism [13]. It is estimated that the $\mathrm{pH}$ of returning stomach contents can even be less than 2.0 [14].

The most important biological factor acting against the harmful effects of acids on the enamel surface is the presence of saliva and its buffering capacity. Simply increasing the amount of saliva, as a reflex reaction, will minimise the damaging effects of acidic substances. Unfortunately, when a significant number of erosive factors overlap, the saliva's defences and capabilities are insufficient [15].

Changes in the lifestyle of young people in recent years have led to an increase in the amount of acidic foods and drinks [16]. This has resulted in a steadily increasing number of people with dental erosion [17]. 
Studies into the frequency of erosion have been carried out throughout the world, but the results are divergent [18]. This seems to be associated with differing criteria for detecting erosive changes, which leads to differences in results and makes them difficult to compare. Hence, the use of a single indicator that would allow for a comparable assessment of the loss of hard tissues of teeth may help improve our knowledge and understanding of the causes and mechanisms leading to destruction of the structure of the teeth. The international standardised BEWE index, proposed in 2008, seems to be an effective testing instrument [19]. It is used to monitor erosive tooth wear progression, but also to compare the tooth erosive risk. The studies conducted so far on Polish populations in seven provinces report the occurrence of erosion in $42.2 \%$ of examined young adults [20]. In turn, a study on a group of 3,187 people aged 18-35 in seven European countries detected at least one erosive lesion in $30 \%$ of the subjects [21]. To compare the erosive tooth wear in young adults in our region, the following examination was conducted.

\section{Objectives}

The aim of the study was to use the BEWE index to assess the level of dental erosion in young adults from the south of Poland.

\section{Material and methods}

260 pairs of plaster casts, made by the same dental technician on the basis of impressions taken on standard impression trays of Kromopan alginate material (LASCOD) and intraoral images, were evaluated. The impressions and photographs were taken by the same researcher (MG) from 260 patients.

To make the casts, a white grade III Stodent Orto plaster (Zermack) was used, prepared in accordance with the manufacturer's instructions, and the surface was fixed with Liquide de lustrage (Dentaurum).

All the photographs were taken using the same digital camera, NIKON D50 (Nikon Corp. Japan), with an AF MICRO NIKKOR $60 \mathrm{~mm}$ (Nikon Corp. Japan) lens, in a maximum intercuspal position and at a slight opening from the front side, both lateral sides and occlusal surfaces of the upper and lower arches. In Figure 1, an example of images and plaster models are shown.

The models and photographs came from volunteers living in the south of Poland participating in project No. N N403 58 9138 of the Ministry of Science and Higher Education, described in the publication of Loster et al. [22]. The volunteers were students aged 17 to 19.1 years invited from three randomly selected high schools in Kraków, Poland. The response ratio was $70 \%$. This group was composed of individuals from the same socio-economic status. The research took place between 2011 and 2013 and was approved by the Bioethics Committee of the Jagiellonian University (KBET/89/B/2009), and the principles of Good Clinical Practice (GCP) were followed during its implementation. Patients undergoing orthodontic treatment with fixed braces and models with identified features of mechanical damage were excluded from the study (9 subjects). Finally, 251 pairs of plaster casts coming from the corresponding number of participants were used in the study.

The Basic Erosive Wear Examination (BEWE) index was used to assess erosive lesions [19]. This is a four-point indicator that is used to evaluate all teeth (except the third molar teeth) on all surfaces, assigning index values of 0 - where there are no symptoms of erosion, 1 - where there is initial enamel loss (initial loss of surface texture), 2 - where there is significant loss of hard tissues on up to $50 \%$ of the surface, or 3 - where hard tissue loss affects over $50 \%$ of the surface. The assessment is carried out in sextants, and only the highest value of the indicator is recorded for each sextant. The cumulative index is obtained by adding the highest scores of the index, and this defines the risk of erosion for a particular patient. The ranges of the indicator values correspond to the following levels of erosion risk: $0-2$ : no risk; 3-8: low risk; 9-13: medium risk; 14 and above: high risk. Proper therapeutic management and check up intervals are recommended for each risk level [19].

All models and photographs were examined by a single person (SPP) after prior calibration. Only the same results from the models and photographs examinations were included to the study. The results of the analysis - in the form of the cumulative BEWE index and the erosion risk - were recorded in a spreadsheet, and this data was taken into consideration in relation to the gender of the study subjects. In order to verify the repeatability of measurements after a month, the test was repeated on five randomly selected pairs of models and photographs.

The results were statistically analysed using $\mathrm{R}$ software, version 3.5.1 [23]. The comparison of values of qualitative variables in groups was made using the chi-square test (with Yates correction for $2 \times 2$ tables) or the exact Fisher test in cases where low expected frequencies appeared in the tables. The level of statistical significance was set at $p<0.05$.

\section{Results}

251 pairs of plaster casts and photographs were qualified to the analysis. Pairs of dental arch models and imagines of 183 women and 68 men were assessed. The study subjects were from 16.7 to 19.3 years of age, with an average age of 17.9 (SD $0.57)$. The prevalence of erosion in the entire study group was $43.43 \%$. In the majority of test subjects identified to have erosion, lesions in the form of an initial loss of enamel (BEWE 1) were observed in $43.03 \%$ of the cases. More advanced lesions were found in one person (BEWE 2).

A slightly higher prevalence of erosive lesions was reported in men $(45.59 \%)$ than in women $(42.62 \%)$, but the results were not statistically significantly different ( $p=0.781$ using the chisquare test) (Table 1).

The value of the cumulative BEWE index for individuals ranged from 0 to 3 (with a score of 0 in $56.57 \%, 1$ in 35.06\%, 2 in $6.37 \%$ and 3 in $1.99 \%$ of the examined models and imagines). The first level ( 0 to 2 scoring points), which presents no risk of erosion, was observed in 246 plaster models and photographs (98.01\%). A low risk of erosion, as the second level of the index ( 3 to 8 points), was diagnosed in 5 cases (1.99\%) (Table 2). There were 3 females and 2 males with low risk of erosion, but the results were without significant statistical differences $(p=0.615$ using the exact Fisher test).

\begin{tabular}{|l|l|l|l|l|l|l|}
\hline \multicolumn{7}{|l|}{ Table 1. Prevalence of dental erosion in all subjects } \\
\hline \multirow{2}{*}{$\begin{array}{l}\text { All subjects } \\
n=251\end{array}$} & $\begin{array}{l}\text { Female } \\
n=183\end{array}$ & \multicolumn{2}{l|}{$\begin{array}{l}\text { Male } \\
n=68\end{array}$} \\
\hline \multirow{2}{*}{$\begin{array}{l}\text { Prevalence } \\
\text { of erosion }\end{array}$} & $n$ & $\%$ & $n$ & $\%$ & $n$ & $\%$ \\
\cline { 2 - 8 } & 109 & 43.43 & 78 & 42.62 & 31 & 45.59 \\
\hline
\end{tabular}

\begin{tabular}{|c|c|c|}
\hline Value of the cumulative BEWE index & $\begin{array}{l}\text { Percentage } \\
\text { of people } \\
n=251\end{array}$ & $\begin{array}{l}\text { Risk of } \\
\text { erosion* }\end{array}$ \\
\hline 0 (No erosive tooth wear) & 56.57 & no risk \\
\hline 1 (Initial loss of surface texture) & 35.06 & no risk \\
\hline 2 (Distinct defect, hard tissue loss) & 6.37 & no risk \\
\hline $\begin{array}{l}3 \text { (Hard tissue loss } \geq 50 \% \text { of the } \\
\text { surface area) }\end{array}$ & 1.99 & low risk \\
\hline
\end{tabular}

* 0-2 of the cumulative BEWE index: 0-2: no risk, 3-8: low risk, 9-13: medium risk, 14 and above: high risk. 

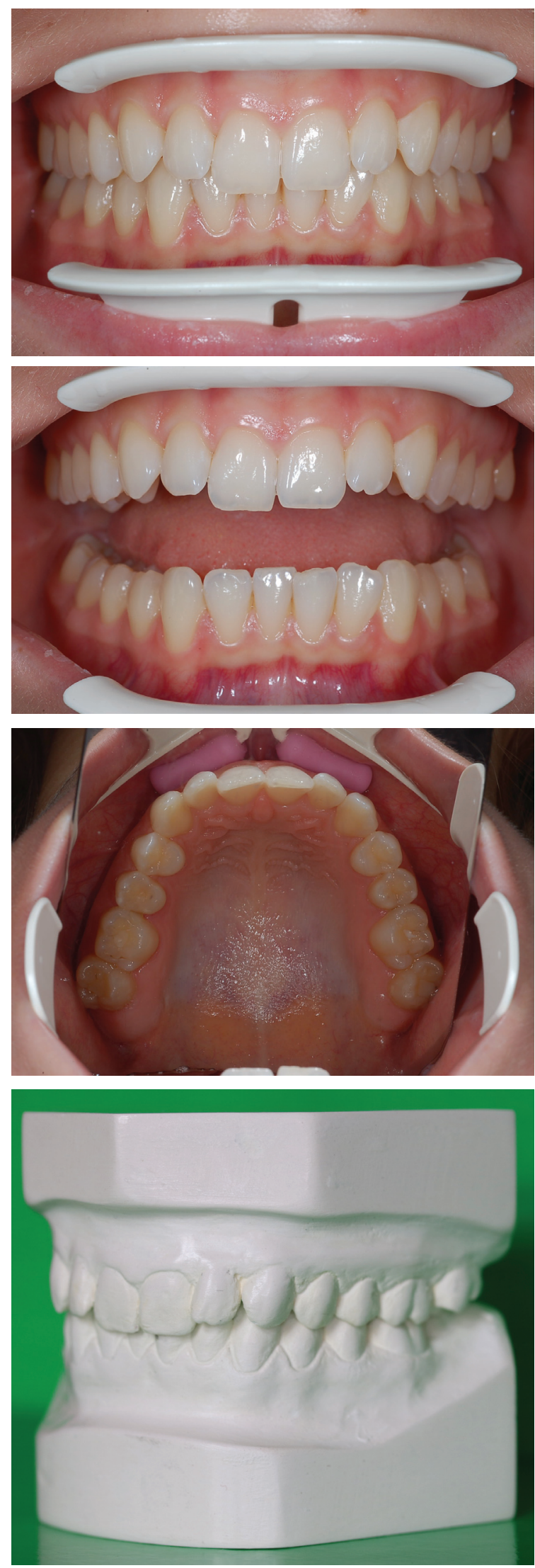

\section{Discussion}

The BEWE index was originally developed not only for clinical use, but also for erosion assessment of dental casts and photographs. This approach may be particularly useful in monitoring individual cases, cross-sectional studies and studies on the incidence of erosion [19]. The advantage of using study mod-
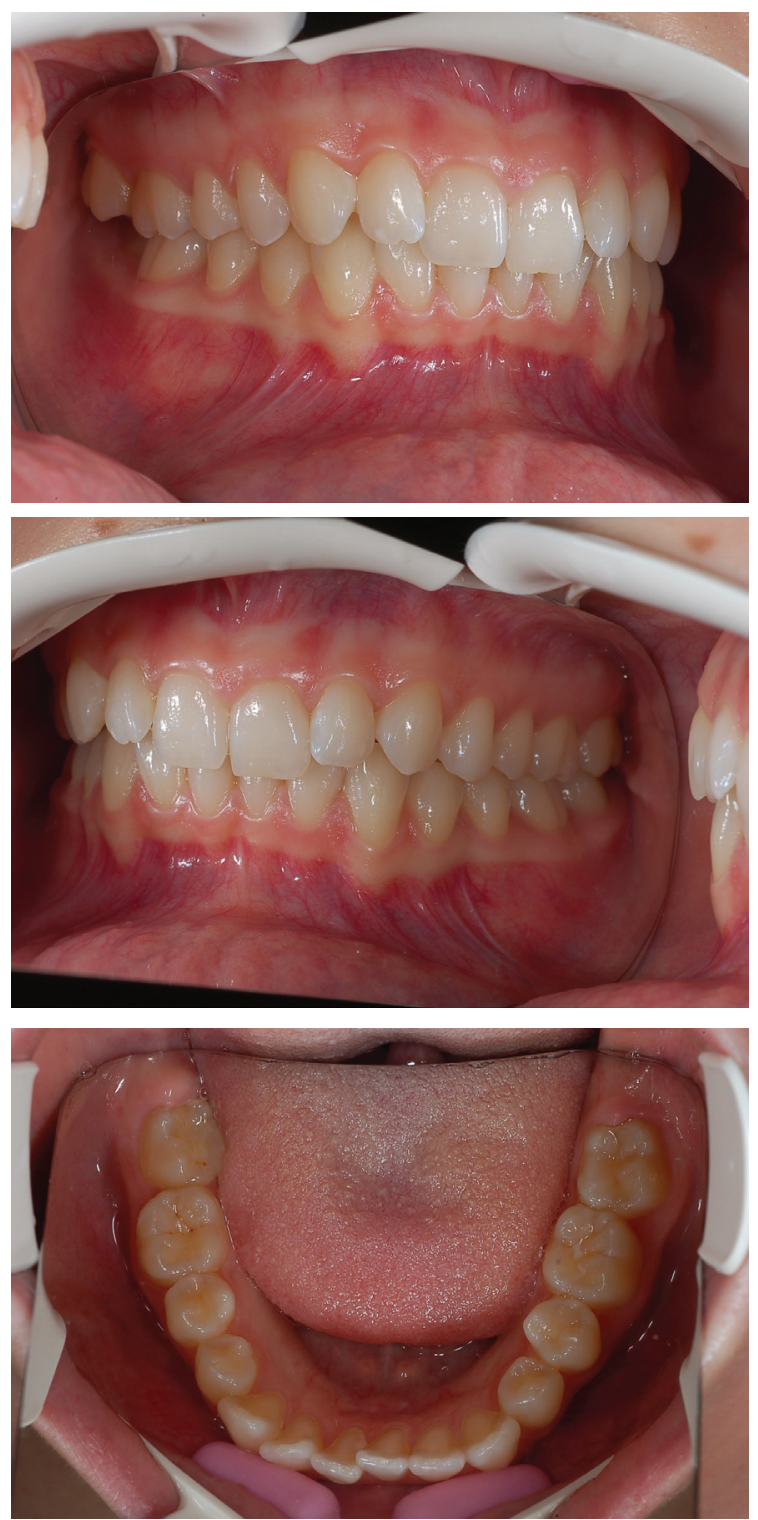

Figure 1. An example of images and plaster models

els is that they can be evaluated multiple times, from different sides, and with optimal lighting. An additional advantage is the lack of time pressure [24]. This is highly effective when comparing the plaster models with the photographs.

Hove et al. assessed the reliability and validity of erosion registration on clinical photographs and plaster casts. The study was carried out by 33 dentists and showed that the diagnosis 
of erosive lesions is as good in clinical photographs and plaster casts [25]. Erosion lesions on models and photographs were also recorded by Linkosalo and Markkanen [26].

A comparison of our results to those of other authors is difficult due to the use of different erosion indices, the small number of studies using the BEWE index and the different age groups examined. However, when referring our results to studies using the BEWE index as part of the "Nationwide Monitoring of Oral Health" conducted by Strużycka et al., a similar prevalence of erosion was found [20]. These authors, who clinically examined the teeth of 1,886 people, found erosion occurring in $42.2 \%$ of patients. Their 18 -year-old subjects came from seven provinces in Poland. Among those diagnosed with erosion, initial lesions were detected most often (28.9\%). As in our study, the authors found this type of erosive lesions to be slightly more frequent in men $(29.1 \%)$ than in women $(28.6 \%)$. More advanced lesions, in the form of hard tissue loss on up to $50 \%$ of the surface (BEWE 2 ) and hard tissue loss on over $50 \%$ of the surface (BEWE 3 ), were detected in $11.9 \%$ and $1.5 \%$, respectively. Relating these results to the research we carried out, we see the Strużycka et al. study to have demonstrated a similar overall number of people affected by the loss of hard dental tissues, though with a slightly higher degree of lesions. This may be due to the much larger quantity of evaluated material. Furthermore, our research could be a complement to Strużycka et al. due to the fact that both studies were conducted at around the same time, and our study included testing of subjects from our region, which was omitted in the study by Strużycka et al.. Moreover, our research, in view of the study design, means examinations of plaster casts and photographs make the results more valuable due to possibility of more precise examinations of all tooth surfaces which might not be visible during clinical assessment.

Kaczmarek et al. obtained slightly different results by assessing dental erosion using the BEWE index in 15-year-old adolescents from the Opole province as part of the "Nationwide Monitoring of Oral Health and Its Determinants" [27]. By conducting intraoral examinations, these authors showed the presence of erosion in $16.6 \%$ of the studied group. The lesions were more frequent in people from urban areas compared to those from rural areas. However, as in our study, they found more frequent erosion in boys than in girls, and the most often discovered lesions were in the form of initial loss of enamel. The cumulative BEWE index for participants with erosion classified them as a group with low risk of erosion, whereas the index for all subjects indicated there was no risk. In our study, the cumulative index for those with erosion indicated no risk $(98.01 \%)$ or low risk of erosion (1.99\%).

Margaritis et al. clinically examined Greek youth aged 14-16 years using three different erosion indices [28]. They showed that erosion occurred in $58 \%$ of the 502 subjects using the BEWE index. The prevalence of erosion was slightly higher in girls than in boys, which makes the results opposite to ours. This may be the result of the age of examined subjects, or it could be due to different dietary habits. Margaritis et al. did not calculate the cumulative index.

Ganss et al. registered erosion lesions of primary and permanent teeth on pre-orthodontic study models. The study included 1,000 plaster cast, 265 of which were followed over a five-year period for the longitudinal assessment using initial and final casts. Researchers used the scoring system of Linkosalo and Markkanen. No erosive lesions were detected in $88.4 \%$ of the models of permanent teeth. At least one tooth with grade 1 erosion was found in $11.6 \%$ of the study group, while $0.2 \%$ had at least one tooth with grade 2 erosion. No erosive lesions were detected in $26.4 \%$ of the models of primary teeth. There was at least one tooth with grade 1 erosion in $70.6 \%$ of the plaster casts, while $26.4 \%$ had at least one tooth with grade 2 erosion. It was found that erosion is a significant, though not serious, problem among adolescents in Germany. With long-term observation, people with erosion in primary dentition showed a greater risk of erosion in permanent dentition [29].

Grzegocka et al., working on the same research material as us, determined that there was a correlation between malocclusion and attrition. Their study showed a high level of abrasion in the teeth of young adults, especially in cases of forced bite and Angle Class II/2 malocclusion. They also demonstrated that the risk of dental abrasion should be considered as an indication for orthodontic treatment [30].

The main strength of this study is the assessment of the dental condition in young adults, which was performed after prior calibration by one researcher on both plaster casts and photographs. However, this study has some limitations, such as the small number of men participating in the study and the lack of history regarding gastrological diseases, eating habits or parafunctions. The clinical implications of our study are that in diagnosing hard tissue loss in young adults, it is necessary to extend the study of erosion aetiology in each individual case.

In summary, our own research indicates that there was no risk of dental erosion for most participants, and there was a low risk in a small percentage. The erosive lesions (except in the case of one person) were initial in character, consisting of a slight loss of enamel; they occurred slightly more often in men than in women. However, among Polish adolescents, the prevalence of erosion was quite high (43.43\%). Although most of the erosive lesions had an initial character, the youth of the study group and the possibility of early stage progression should be taken into account. Additionally, if we compare the research made in our city with that by Fijał et al. [31] over 20 years ago in 1989-1991, we can see that in that period of time, in the female group aged 15 to 20 years, $100 \%$ had no erosions lesions, and in the male group, $88.46 \%$ were without any lesions. Non-carious lesions were found in only $7.14 \%$ of those examined. This can show that the eating habits in that time did not predispose dental hard tissue loss. With reference to the data reported by other authors concerning the ongoing increase in the development of erosive lesions, research in this field should be continued.

\section{Conclusions}

There was no risk or a low risk of erosion among the studied adolescents; however, given the findings of other authors, the study should be continued, and the examined group of young adults should be called for check-up examinations to monitor their tooth condition. The use of the BEWE index made it possible to detect erosive lesions on the permanent teeth of a group of young adults. The risk of erosion among the studied adolescents was at a similar level as in other countries and occurred slightly more often in men than in women.

The family doctor is often the first person who has contact with the patient and is the first to recognise dental erosion. Early diagnosis and dietary advice can prevent the progression of erosive lesions.

Source of funding: This work was funded from the authors' own resources.

Conflicts of interest: The authors declare no conflicts of interest.

\section{References}

1. Ganss C. Definition of erosion and links to tooth wear. Monogr Oral Sci 2006; 20: 9-16.

2. Lussi A, Schlueter N, Rakhmatullina, E, et al. Dental erosion - an overview with emphasis on chemical and histopathological aspects. Caries Res 2011; 45(Suppl. 1): 2-12. 
3. Milosevic A. Toothwear: aetiology and presentation. Dent Update 1998; 25: 6-11.

4. Lussi A, Jaeggi T. Chemical factors. Monogr Oral Sci 2006; 20: 77-87.

5. Larsen MJ, Nyvad B. Enamel erosion by some soft drinks and orange juices relative to their pH, buffering effect and contents of calcium phosphate. Caries Res 1999; 33: 81-87.

6. Zero DT, Lussi A. Behavioral factors. Monogr Oral Sci 2006; 20: 100-105.

7. Moss SJ. Dental erosion. Int Dent J 1998; 48: 529-539.

8. Moazzez R, Smith BG, Bartlett DW. Oral pH and drinking habit during ingestion of a carbonated drink in a group of adolescents with dental erosion. J Dent 2000; 28: 395-397.

9. Millward A, Shaw L, Harrington $\mathrm{E}$, et al. Continuous monitoring of salivary flow rate and $\mathrm{pH}$ at the surface of the dentition following consumption of acidic beverages. Caries Res 1997; 31: 44-49.

10. Ganss C, Schlechtriemen M, Klimek J. Dental erosions in subjects living on a raw food diet. Caries Res 1999; 33: 74-80.

11. Herman K, Czajczyńska-Waszkiewicz A, Kowalczyk-Zając M, et al. Assessment of the influence of vegetarian diet on the occurrence of erosive and abrasive cavities in hard tooth tissues. Postepy Hig Med Dosw (Online) 2011; 65: 764-769.

12. Scheutzel P. Etiology of dental erosion - intrinsic factors. Eur J Oral Sci 1996; 104: 178-190.

13. Bartlett D. Intrinsic causes of erosion. Monogr Oral Sci 2006; 20: 119-139.

14. Lazarchik DA, Filler SJ. Dental erosion: predominant oral lesion in gastroesophageal reflux disease. Am J Gastroenterol 2000; 95: S33-S38.

15. Hara AT, Lussi A, Zero DT. Biological factors. Monogr Oral Sci 2006; 20: 88-99.

16. Lussi A, Erosive tooth wear - a multifactorial condition of growing concern and increasing knowledge. Monogr Oral Sci 2006; 20 : 1-8.

17. Jaeggi T, Lussi A Prevalence, incidence and distribution of erosion. Monogr Oral Sci 2006; 20: 44-65.

18. Carvalho TS, Colon P, Ganss C, et al. Consensus report of the European Federation of Conservative Dentistry: erosive tooth wear - diagnosis and management. Clin Oral Investig 2015; 19: 1557-1561.

19. Bartlett D, Ganss C, Lussi A. Basic Erosive Wear Examination (BEWE): a new scoring system for scientific and clinical needs. Clin Oral Investig 2008; 12(Suppl 1): S65-S68.

20. Strużycka I, Rusyan E, Bogusławska-Kapała A. Prevalence of dental erosion in young adults aged 18 years in Poland. Przegl Epidemiol 2014; 68: 689-693.

21. Bartlett DW, Lussi A, West NX, et al. Prevalence of tooth wear on buccal and lingual surfaces and possible risk factors in young European adults. J Dent 2013; 41: 1007-1013.

22. Loster JE, Osiewicz MA, Groch M, et al. The prevalence of TMD in Polish young adults. J Prosthodont 2017; 26: 284-288.

23. Team RC. A language and environment for statistical computing. Vienna, Austria: R Foundation for Statistical Computing; 2019.

24. Johansson AK, Johansson A, Birkhed D, et al. Dental erosion, soft-drink intake, and oral health in young Saudi men, and the development of a system for assessing erosive anterior tooth wear. Acta Odontol Scand 1996; 54: 369-378.

25. Hove LH, Mulic A, Tveit AB, et al. Registration of dental erosive wear on study models and intra-oral photographs. Eur Arch Paediatr Dent 2013; 14: 29-34.

26. Linkosalo E, Markkanen H. Dental erosions in relation to lactovegetarian diet. Scand J Dent Res 1985; 93: 436-441.

27. Kaczmarek U, Kobierska-Brzoza J, Fita K. Prevalence of dental erosion in 15 -year-old subjects from Opole province. Dent Med Probl 2012; 49: 189-194.

28. Margaritis $\mathrm{V}$, Mamai-Homata $\mathrm{E}$, Koletsi-Kounari $\mathrm{H}$, et al. Evaluation of three different scoring systems for dental erosion: a comparative study in adolescents. J Dent 2011; 39: 88-93.

29. Ganss C, Klimek J, Giese K. Dental erosion in children and adolescents - a cross-sectional and longitudinal investigation using study models. Community Dent Oral Epidemiol 2001; 29: 264-271.

30. Grzegocka K, Williams S, Loster JE, et al. Relationship between occlusion and dental attrition in a group of young Polish adults. J Stoma 2016; 69: 285-294.

31. Fijał D, Kaczmarczyk-Stachowska A, Knychalska-Karwan Z, et al. The incidence of non-carious lesions in the 15-80 year old Cracow population. Czas Stomatol 2001; 54: 636-641.

Tables: 2

Figures: 1

References: 31

Received: 23.09.2019

Reviewed: 02.10.2019

Accepted: 17.02 .2020

Address for correspondence:

Sylwia Przybyszewska-Pardak, MD

Katedra Protetyki Stomatologicznej

Instytut Stomatologii

Uniwersytet Jagielloński Collegium Medicum

ul. Montelupich 4

31-155 Kraków

Polska

Tel.: +48 12 424-55-55

E-mail: sprzybyszewska-pardak@uks.com.pl 